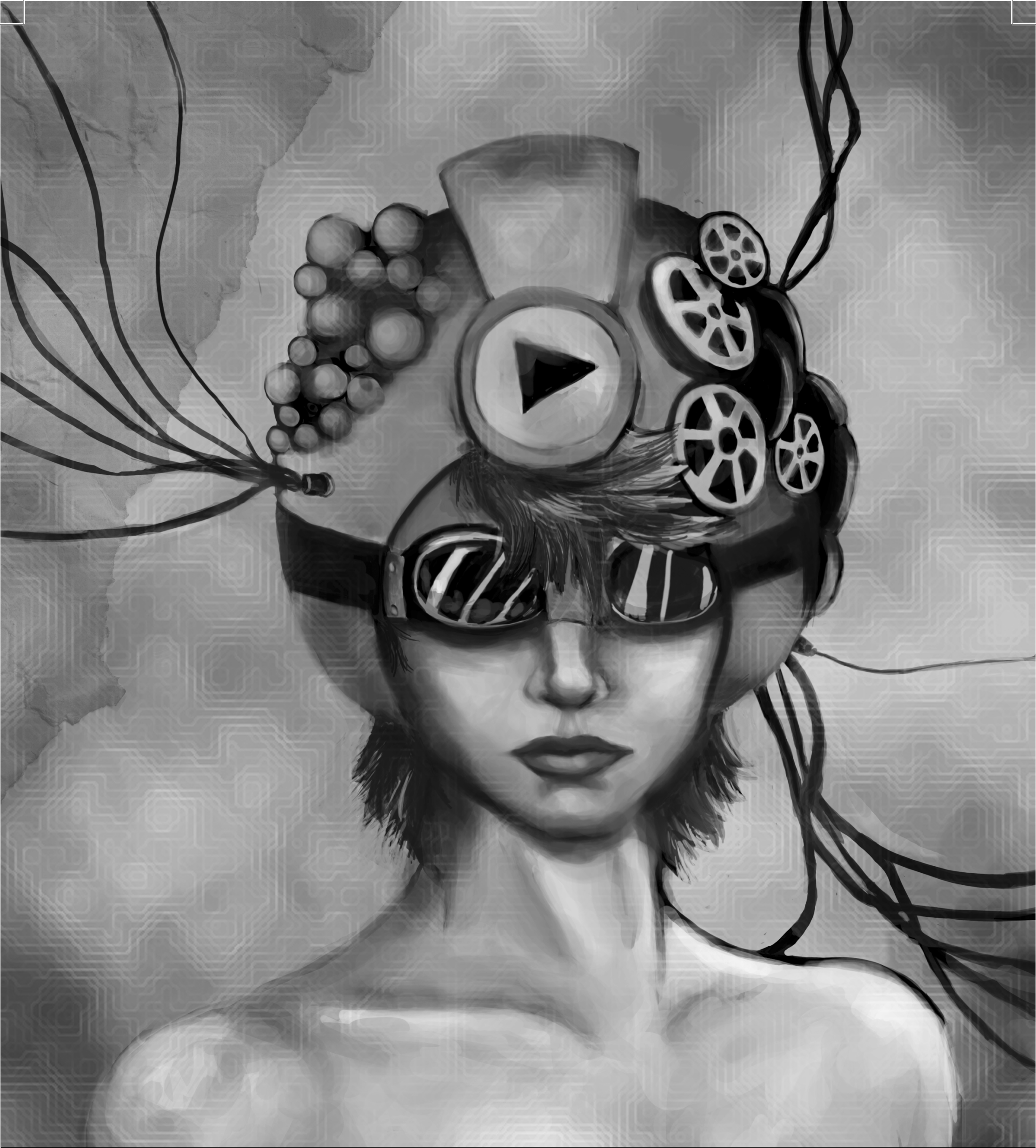

Traductores multimediales. Sugerencias, perspectivas y nuevas reflexiones de la oralidad urbana en Colombia 


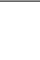




\section{Traductores multimediales. Sugerencias, perspectivas y nuevas reflexiones de la oralidad urbana en Colombia}

\author{
Alexander Díaz Gómez \\ Politécnico Grancolombiano \\ diazgom@poli.edu.co \\ Filósofo. Universidada de los Andes. Master en \\ comunicación Pontificia Universidad Javeriana.
}

Fecha de recepción: 22 de julio de 2011

Fecha de aceptación: 8 de septiembre de 2011

\section{Resumen}

La oralidad permanece en un estado latente en las dinámicas simbólicas de una sociedad mediática. Es evidente que esta tendencia se ha convertido en una verdadera resistencia cultural e, incluso, en una forma que busca afianzar algunos puntos importantes de la identidad de los pueblos que aún utilizan la oralidad. Los chats y las redes sociales, conservan la dinámica de la oralidad. Este escrito es una aproximación a un fenómeno que atraviesa otras atmósferas semióticas: las une, las convierte en formas que realzan la vieja tradición de contar cuentos, pero con un lenguaje completamente nuevo. La visión de esta investigación es una mirada al fenómeno que en apariencia es superficial, pero que lleva en sí mismo, la esencia de una cultura post-mediática e hipervincular.

\section{Palabras clave}

Oralidad, tradición oral, semiótica, rituales, interacción, cuentería.

\begin{abstract}
Oral tradition remains latent in the symbolic dynamics of a media society. It is evident that this tendency has now become a true cultural resistance and even a form that looks for consolidating some important points of the identity of the towns that still use oral tradition. Chats and social networks conserve the dynamics of oral tradition. This writing is an approach to a phenomenon that crosses other semiotic atmospheres: it unites them, turns them into forms that heighten the old tradition to tell stories, but with a completely new language. The vision of this investigation is a glance to the phenomenon that in appearance is superficial, but that takes in itself the essence of a post-media and linking culture.
\end{abstract}

\section{Keywords}

Orality, Oral Tradition, Semiotic, Rituals, Interaction, Storytelling. 


\section{Oralidad y sugerencias}

Debo confesar que envidio profundamente a los traductores simultáneos: deciden en un momento cuál es el mejor término o concepto que coincida, no sólo la palabra correcta, sino además la intención de su interlocutor; así que debe tener el conocimiento de dos o más grupos de significados lingüísticos, costumbres y modismos para interpretar lo dicho. Así, por medio de los signos, se dice que una lengua es capaz de ser traducida. Aún más, sería inquietante asignarle ese papel de traductor de lenguajes diferentes a aquellos que encuentran su oficio en alguna semiósfera de su propia lengua ${ }^{1}$. Ese es el caso de aquellos que por medio de un lenguaje como el oral, establecen contextos de un "compromiso colectivo de una comunidad". Por medio de un lenguaje, se elaboraría una serie de señales para facilitar la ordenanza de un cuerpo social en miras de "disipar sus propias contradicciones". Las imágenes no son traducibles sólo en palabras y mostrar una imagen desde el lenguaje oral convoca una legión de interpretaciones, puede elaborar una impresión sobrecogedora (Piscitelli, 2002). Ahora mismo, cuando el mundo se ha dinamizado y ha convocado conglomerados humanos que conviven con las nuevas tecnologías globales de la comunicación y la información donde se prima la imagen, existe un hecho que mantiene la oralidad aún en estado latente. Es cierto, una imagen vale más que mil palabras pero una palabra puede convocar mil imaginarios posibles.

La imagen va al frente del vocablo, pero el sonido va por delante de la imagen (Piscitelli, 2002). Tal hecho todavia es posible en un conglomerado que presenta una resistencia cotidiana por medio de la oralidad; un conglomerado que conserva en pequeños nodos a los heraldos héroes que cuentan historias frente a una modernidad cada vez más líquida ${ }^{2}$. Los narradores orales pueden ser justamente como traductores nómadas de las historias que llegan a sus bocas: transforman por medio de su performance las viejas historias en

1 Todo el concepto de semiósfera, es decir los momentos semióticos de la humanidad, pueden resumirse en tres. Logosfera: es el momento de la palabra; grafósfera: el momento del mundo escrito; videósfera: la supremacía de la imagen. Cfr. Debray, Régis. (1994). Vida y muerte de la Imagen.Comunicación 58. Para profundizar en el particular Cfr. Lotman y sus semiósferas. nuevas interpretaciones frente al Mc mundo 3 . Así, lo oral, aunque se entrecruza con un entorno visual y aunque existen los networlds, mundos-redes, donde nos tele-encontramos virtualmente, subsisten los mundos cotidianos; puntos de encuentro posibles en los espacios de cuentería y en otros lugares como las redes sociales donde justamente se reactiva la dinámica de una historia personal que se cuenta para que otros sean testigos de ella. Incluso hay grupos de Facebook que invitan a escuchar cuentos en espacios fuera de red. Un narrador oral que posee al mismo tiempo lo viejo de su profesión y lo nuevo por contar, navegaría en el flujo mismo de las historias, representando un quehacer tanto simbólico como significativo, en el conglomerado social al cual pertenece. ¿Serían los nuevos narradores -los "cuenteros"- verdaderos mediadores entre la realidad, los sujetos y sus interpretaciones?

A esta cuestión se le suma un hecho particular, porque algunos universitarios en los últimos veinte años (si somos estrictos cinco generaciones de universitarios, pensando que una carrera profesional en promedio dura cinco años) y transeúntes de las calles de las principales ciudades colombianas en los últimos diez años, escuchan cuentos e historias en espacios abiertos o cerrados, sin que exista en ese hecho ningún tipo de transmisión ideológica explícito que lo promueva, buscando, tal vez, entender e interpretar el mundo que los rodea y con este hecho tener elementos que los estructuren como sujetos simbólicos de su entorno.

Todo esto es lo que me impulsa desde el 2007 a buscar las razones de un hecho tan evidente de la permanencia de las dinámicas orales en un mundo entrecruzado por semiósferas que resaltan el valor de lo audio-tecno-visual. Son cuestiones simples y al mismo tiempo inquietantes: ¿por qué la gente escucha cuentos en una cultura mediática como la nuestra? ¿Existe una diferencia entre la forma de escuchar historias en las actuales dinámicas hiper-vinculares?

3 Entendemos como performace a todo el acto que tiene un narrador oral en su encuentro con la oralidad frente a su público: voz, menaje, cuento, intención, incluso su relación hermenéutica con el público. Cfr. Vich, Victor et al., "Oralidad y poder". Introducción. 


\section{Primeras consideraciones en las dinámicas orales en el mundo hipervincular y sugerencias}

En el estudio que emprendí -casi creyéndome un traductor- era mi intención argumentar que en donde se efectuaba la cuenteria y en los cuenteros mismos, como representantes actuales de la oralidad, se presentaba un entrecruce entre el lenguaje video-lecto-escrito y simbolos propios de una sociedad movida por los medios masivos de comunicación. Era mi deseo argumentar que en este momento de la historia, nuestra sociedad podría contener en su interior un punto intermedio e híbrido entre las directrices del cine, la televisión y la red de información. Una alternativa latente que resiste pasivamente a las verdades de la videósfera: un cierto ágora donde el individuo es miembro de un grupo se creería parte de su entorno sin dejar su carácter personalizante, tratando así de defender en las redes sociales o la globalización galopante su individualidad, su "brillo" particular"; este lugar donde las combinaciones constantes de escrituras y métodos todavia resiste desde el mundo de las sugerencias y de las metáforas, un acontecimiento social que se desenvuelve en Latinoamérica.

El paso siguiente a ese argumento que lo reforzaba, rezaba que, si bien es cierto que los narradores comparten y viven en dinámicas semióticas atravesadas de fenómenos postmediáticos, ellos recurren a herramientas que existen desde el comienzo de la especie: explicar un entorno, reflexionar sobre el ser en el mundo y cómo es afectado; utilizar un estilo formulario en los relatos efectivos de cada generación del conglomerado social determinado.

En ese orden de ideas, la génesis del fenómeno de la narración oral entendida como cuentería puede centrarse en las siguientes jornadas, que son en sí mismas sugerencias de la interacción entre la oralidad y las otras semiósferas ${ }^{5}$ : el rescate, la creación e interpretación, la saturación de herramientas y la diversificación de espacios donde discurre el encuentro oral en una sociedad supuestamente no-oral.

4 Cfr. Blog http://fashionmedia.blogspot.com/2008/03/moda-y-globalizacin-prdida-de-la.html extractado el día junio 16 de 2010.

5 Cfr. La caracterización de la narración oral entendida como cuentería en Pérez Ángela María "Revive la Palabra" editorial Uniandes 1999. Introducción.

\section{Sugerencia 1. Así como en "El Fedro" hay discusión sobre la memoria, se desea respetar y rescatar la tradición.}

En un primer momento, el esfuerzo de los narradores que rescatar la cultura oral en nuestro país en 1988 (e incluso antes) era el resultado de una oralidad latente que permanecía en la periferia como si fueran encuentros de sabiduria popular ${ }^{6}$. Tres años después, los narradores empiezan a contar historias más allá de las tradiciones, mezclando cuentos con historias urbanas y relatos de vida cotidiana, además de cuentos provenientes incluso de la literatura, contados como adaptaciones o de forma literal.

\section{Sugerencia 2. Los nuevos narradores se aventuraron con sus alas nuevas, como Ícaros sobrevolando Gnosos.}

Con el tiempo, estos mismos espacios forjaron una "generación" de narradores que utilizaban herramientas propias de un lenguaje televisivo y cinematográfico, producto de su propia generación. En los espacios de cuentería, desde esa propuesta hasta ahora, algunos relatan historias llenas de significados simbólicos derivados del mundo mediático.

\section{Sugerencia 3. Se esperó la llegada de la mano invisible, pero no hubo regulación del mercado.}

En la misma dinámica de ese "movimiento" frugal de narradores orales, los problemas del mercado se hicieron evidentes: los jóvenes narradores que no provenían de espacios convencionales de narración deseaban ser escuchados y decidieron crear espacios no convencionales. En este punto se contaba en bares, parques, transporte urbano y restaurantes; era un hecho efectivo y económico que lentamente se masificó saturando las herramientas que caracterizaban a la "cuentería urbana" como una línea que mostraba la realidad de los jóvenes y la hilaridad de sus posibles reflexiones.

Cfr. Abadía M., Guillermo. 


\section{Sugerencia 4. Cada uno por su lado: ¿el que hace reír sobrevive?}

Cada estilo de narración empezó su sendero, empezó a sobrevivir y tener visibilidad frente a los otros: los espacios universitarios mantuvieron su carácter híbrido en estilos y líneas narrativas; los espacios de calle empezaron a experimentar con la comedia y dinámicas de teatro callejero; los espacios convencionales programaron narradores que contenian estéticas literarias, artísticas e interpretaciones orales. Fue allí donde los espacios diversificaron la oralidad.

Fue en este contexto, entre los años 1990 y 2005, cuando la cuentería universitaria en Bogotá se volvió una evidencia palpable de la forma como se "modernizaba" la oralidad en nuestra sociedad.

Me rondó en la cabeza un término que se me antojó apropiado para tal fenómeno: la cuenteria podria ser postmediática. Pero frente a la expresión surgió la dificultad del posible trabajo de campo. Éste se realizaría en eventos de cuentería masivos entre 2006 y 2009. Más exactamente en el evento denominado Narratón, efectuado por una emisora capitalina por tres años consecutivos en el día del idioma. El evento consistía en contar por más de 24 horas, cuentos en la radio comercial, pero además con presencia de público afuera de la emisora. En 2004, la Narratón había alcanzado un público de 400 personas. Una de las características del evento se enmarcaba en que los narradores utilizaban herramientas mediáticas como comerciales y personajes de seriados televisivos (el comercial de Salsa de tomate Fruco donde tres sujetos se lanzan en la nieve y gritan "ra-ra", los comerciales de Prismacolor: "al tigre se le borraron las rayas", hablar de Daniela de Padres e hijos, entre otros) además de utilizar escenas de películas para hacer de sus cuentos más efectivos ("The Matrix" o "El señor de los anillos").

Es más, entre 2005 y el 2008 se desarrolló una muestra de narración oral de gran impacto en el Festival de Verano de Bogotá (Colombia), mostrando así varios estilos provenientes de las posibles vertientes orales esbozadas más arriba: narradores universitarios, narradores utilizando al "personaje narrador" y cuenteros tradicionales. Los universitarios eran los que más utilizaban herramientas de origen mediático (referentes de la televisión, telenovelas del momento, sucesos actuales de fácil recordación) con una participación de dos mil a diez mil personas escuchando historias, tanto en el Palacio de los Deportes, como en el parque de los novios.

Estos acaecimientos eran óptimos para la investigación y me llevaron a pensar en un momento donde los medios masivos y los "relatos mediasféricos" que presenta Régis Debray en su Vida y Muerte de la Imagen estaban presentes, utilizando una diversidad de herramientas que comprobaban una y otra vez que la oralidad se adaptaba por medio de los narradores orales de las actuales dinámicas mediáticas o en ese momento postmediático.

El primer entusiasmo dio paso al sentido común frente a la expresión postmediático: no hemos superado lo mediático (aunque nos encontremos mezclándolo con lo digital), estamos todavía inmersos en ellos y la experiencia que tenemos de los medios masivos nos puede convertir en tribus tele-informáticas que tejemos nuestras nuevas urdimbres simbólicas.

Prueba de ellos es que, con el tiempo, la emisora canceló el evento porque no "era rentable". De la misma manera, el impacto de narraciones orales de gran formato fue poco a poco perdiendo novedad, y aunque existen aún ahora grandes eventos masivos, la afluencia del público no es la misma que en años anteriores. Lejos estoy de reflexionar sobre el estado de los espacios universitarios: lo que se había presentado con grandes dinámicas en la década del noventa con el surgimiento de casi veinte espacios en las universidades del centro del país, al término de la década resultó convertido en sólo cinco espacios.

Algo cambiaba: las nuevas generaciones utilizaban la oralidad en otros espacios diferentes a donde participaba a finales del siglo; las metáforas habian cambiado y no entendía cuál era el actual papel de la oralidad en las dinámicas del conglomerado colombiano.

Después de un cierto relevo simbólico, observamos a las nuevas generaciones atravesadas por los medios masivos de comunicación, utilizando las herramientas mediáticas y aun conservando (pero con menos impetu) los espacios de narración oral y los encuentros con los narradores orales como un lugar de identificación, encuentro y socialización de sus realidades. 


\section{Nuevos caminos, viejos conocidos}

Con esas reflexiones, pensé en una exploración iniciando con la comparación de los elementos que componen a la oralidad como la entiende Walter Ong: existe un momento primario puro y uno secundario, lleno de combinaciones donde "nos encontramos". Pensando que la palabra postmediático podría considerarse algo para debatir sin pruebas más concretas de un momento posterior, pensé en poner el término oralidad neomediática: un momento donde la oralidad secundaria de la que habla Ong, estaría en camino a dar un paso por el inmenso entrecruce de su red de significados simbólicos, en una elaboración o resignificación de la cultura masiva, como en efecto sucede con las redes sociales, los blogs o los teléfonos Blackberry.

La nueva cuestión giraba en torno a localizarnos en las dinámicas semióticas. Encontré entonces en Piscitelli una posible respuesta: es probable que la oralidad genere un espacio virtual que está redefinido por no sólo la era de lo mediático, sino por la era post-escritural. Es cierto: "las tecnologias de la memoria se suman a las de la inteligencia" fundando inéditas esferas, persuasiones culturales y ambientes imaginativos novedosos. El momento de los nuevos ensamblajes culturales, determinados por nuestra relación con los medios masivos, se pueden brindar la posibilidad real de combinación entre la oralidad y los modos audiovisuales de los media. Una mezcla e hibridación con los nuevos significados, creando una alteridad, una posible oralidad transformada y en constante evolución.

En ese punto de la investigación cavilé en lo siguiente: los espacios de cuentería primero, y los cuentos que cuentan los nuevos cuenteros, son el resultado de un nuevo ambiente novedosos, un posible ambiente virtual donde la oralidad ha sufrido un cruce constante, indetenible, dinámico, traductor de realidades latentes. Tal mezcla semiótica puede verse en la utilización de instrumentos mediáticos en el interior de las narraciones hechas por los hijos de una cultura audiovisual, pero herederos de la oralidad primigenia. Y no sólo allí, sino en el cuerpo mismo de la narrativa contemporánea influenciada por la presencia de las herramientas audiovisuales, e incluso técnicas, con la aparición por ejemplo del hipertexto o los intercambios escriturales del chat o la video conferencia.
¿Es posible considerar a la cuentería un espacio virtual? Sabemos por Quéau, que en la oralidad nunca dejamos el cuerpo en ese campo, no hay des-carnación aunque en los momentos de la cuentería pueda existir una especie de liberación simbólica. Aún más, existe una voluntad real de des-imaginación (Quéau, 1995). Para Quéau no se pretende en los espacios virtuales prescindir de las imágenes, sino comprenderlas en su esencia intentando así depurar lo que se imagina. Es probable que exista una polisemia inagotable en la imagen que en la palabra no exista, pero por medio de la sugerencia nuestra imaginación salta a lugares aún inexplorados (Debray, 1994).

\section{Lo virtual y más palabras raras}

Lo recorrido da una imagen de múltiples voces en las tecnologías de la memoria (Ong, 1996): se cuestiona la necesidad real de escuchar historias en un medio atravesado por nuevas estructuras de significado. Nos encontramos con el breve entusiasmo de una oralidad postmedia pero comprobamos brevemente que los jóvenes también están utilizando la oralidad, entendida como cuentería, en otros espacios diferentes a los presentados en los últimos veinte años del siglo veinte y primeros siete del nuevo milenio. Después de un cierto relevo simbólico, observamos a las nuevas generaciones atravesadas de los medios masivos de comunicación, utilizando las herramientas mediáticas y aun conservando los espacios de narración oral y los encuentros con los cuenteros como un lugar de identificación, encuentro y socialización de sus realidades. Ahora hemos llegado a este nuevo ambiente que es el marco de lo virtual, tan novedoso e interactivo pero al mismo tiempo cerrado. Éste puede seducir nuestros sentidos y saturarlos.

En las historias que se cuentan tal vez exista un modelo inteligible; por medio de la sugerencia de una historia hay depuración de la imaginación. En el mundo oral hay un proceso simultáneo, un vínculo entre el que cuenta y el que escucha. En los cuentos que se cuentan, no importa si son de narración oral tradicional o urbanos, si son de comedia del arte o relatos adolescentes, existe un universo intimo, un espacio imaginado por la forma como el público se involucra. Puede ser un espacio virtual porque se produce "una multitud cambiante de metáforas", de sugerencias donde todavia se comulga con la idea de un narrador como un artista intermedio porque sienten lo que 
cuentan como parte de ellos y concurre una interacción con el público; incluso en los niveles más altos de la interacción producto de la virtualidad, hay historias que contar y público que las escucha. La narración oral ahora se incluye en ese nuevo espacio virtual (tal vez nunca lo ha dejado).

¿Sobrevive la oralidad a los avatares de las nuevas tecnologias? La respuesta es afirmativa: aquí o allá se narran historias, se crean imaginarios.

\section{Sin evitar hablar de la vida de los cuenteros y la observación participante sobre el particular}

Así me topé en la investigación con la necesidad de mezclar mi voz y mi saber con la de aquellos que consideraba mis pares generacionales en el fenómeno oral, con el objetivo de desentrañar las posibles herramientas mediáticas que tomaba para la elaboración y puesta en escena de sus relatos

Antes de las entrevistas, debo anotar que realicé una observación de dos espacios en particular: uno universitario y formal, el espacio de "La Perola" de la Universidad Nacional de Colombia, y un espacio de calle: La plaza "Fundadores", para observar cuál era su funcionamiento y sus dinámicas internas. Esta observación tuvo en la parte metodológica un problema: mi nombre como narrador y mis cuentos son visibles para las nuevas generaciones de cuenteros. Tanto en el espacio universitario como en el de calle existe lo que se denomina el derecho de piso. Si un cuentero de trayectoria llega a estos espacios, por haber contado antes allí, tendrá la invitación de contar si lo desea.

Para mi suerte en los días que acudí al espacio de Usaquén (espacio callejero), sólo había un cuentero que me conocía. Los cuentos que contaban los nuevos narradores eran los mismos que habian escuchado en otros espacios o de "oídas". Varios cuentos de mi autoría fueron contados en ese espacio: algunos decian que lo habian escuchado de alguien pero que sabían que era de Alexander Diaz, "Mateo".

Un narrador tradicional, Omar Díaz, "Juansinmiedo", les indicó a los nuevos narradores que el autor de los cuentos se encontraba allí y se abstuvieron de seguir contando, no sin antes invitarme a contar. Sin embargo en esa ocasión me aventuré a la observación participante.

Desde que se llega a un espacio de cuentería, uno se encuentra con hechos particulares. Cuando se espera en un espacio universitario que empiecen los cuenteros, estudiantes de distintas carreras están pendientes. En "La Perola" de la universidad Nacional de Colombia, ocurre siempre lo mismo: existe un presentador o conductor del espacio, que saluda y convoca a la gente circundante que aún no ha tomado asiento. Luego se presenta a los invitados de turno, en ocasiones la gente que espera la cuentería se emociona al escuchar el nombre del que viene a contar en su espacio (en la Nacional el espacio es semanal).

E1 espacio callejero es diferente. Existe un grito generalizado que rompe con la rutina del lugar donde se ha escogido contar convocando al público transeúnte: en ocasiones en un espacio como el de Maloka (espacio no convencional que funciona desde hace una década), existe la misma dinámica de saludo y convocatoria anteriormente descrita.

Una diferencia observable con los espacios uiniversitarios es la edad del público, ésta varía desde adolecentes de 12 años, hasta sujetos de 40 años con sus familias. En Usaquén se pasa la mochila o sombrero porque no hay apoyo institucional. La mochila varía de lugar y dependiendo del público, pero oscila entre los 90 mil y los 380 mil pesos.

Desde mi experiencia como narrador oral, puedo anotar que es por esa facilidad de dinero que los nuevos narradores no estan creando nuevas propuestas narrativas sino que repiten constantemente los cuentos ya existentes, variándolos de tal manera que pueden desfigurar su contenido por el habiente de jococidad que deben manejar en los espacios de calle. En otras palabras, "chabacanizan" (si se me permite la expresión) los relatos, como veremos cuando toquemos la entrevista con el cuentero tradicional.

Ahora bien, en el espacio de Narración de "La Perola" se organiza una narratón de seis horas donde se convocan todos los estilos de cuentería. Entrevisto así, de manera muy informal, al cuentero que actualmente es más representativo de los cuenteros universitarios: Harry Marín Vahos. Él es médico de la Universidad 
Nacional y representante por Colombia de Abrapalabra 2002. Es cuentero desde hace seis años y fue coordinador del espacio de "La Perola" por dos años antes de realizar sus estudios de postgrado. Planteo en la entrevista que la tradición oral podría encontrarse en estado latente en esta cultura llena de imágenes y que toma prestadas herramientas, sonidos, sugerencias (que remiten a la cultura grafa y la mediática) que representan verdaderos entrecruces de significado y Harry me comprueba tal sugerencia. Los cuentos de Harry son en su mayoria literarios o provenientes de la cultura gráfica. Uno de los cuentos más característicos es una adaptación de un cuento de Kostas Axelos que se llama "La verdad".

Concurre una identificación del público con lo que el cuentero está contando, ese fue el primer aporte dentro del cuerpo de las entrevistas. En cuanto a una categorización de los narradores, surge el cuentero universitario. Éste proviene de la academia grafa y tiene una formación literaria (en algunos casos no). Los narradores utilizan gags de humor para enganchar y mantener al público, además de manejar herramientas que provienen de la televisión y del cine (Sol \& Turk, 2010)ㄱ.

-A.D.: ¿Tú sientes que el narrador utiliza elementos que aparezcan en televisión, en radio, en cine como una herramienta para que el público se sienta identificado?

-H.: Claro, claro.

-A.D.: ¿Cuáles serian para ti esas herramientas, o al menos las que tú has visto y percibido en los trabajos de otros que hayas escuchado o en el tuyo mismo?

$7 \quad$ Uno de los puntos que deseo analizar frente a los entrecruces de los medios masivos como un fenómeno comunicacional y la cuentería (universitaria y de calle) es la semejanza que puede tener con la comedias de situaciones o el "Sit-Com", que es utilizado con frecuencia en la televisión de Estados Unidos y en algunos proyectos cinematográficos. Desde la propuesta narrativa de López y la generación de cuenteros que contaron la cotidianidad, poco a poco en los espacio callejeros y en los universitarios se incluyeron más algunos elementos situacionales y menos los elementos narrativos. Es decir, la historia en algunos momentos que convertía en una excusa para poder "poner" en escena a los personajes de la misma, en una situación que a la postre resultara llamativa para el público asistente, que toman de una forma amena, situaciones que el cuentero expresa en algunas historias. Es curioso como el fenómeno ahora alcanza las dimensiones propias de comedia con la incursión de Diego Camargo, Diego Mateus y Gonzalo Valderrama en el fenómeno de la Stad up comedy.
-H.: Bueno, yo creo que el cine y la televisión han marcado definitivamente toda esta generación. Hemos sido una generación que cambió los juegos manuales por los juegos de video, que dejó de escuchar cuentos para verlos, que dejó de conversar para que otro le hablara a través de la televisión, pero que se estrella contra un sujeto que utiliza esos mismos recursos y los convierte en oralidad. Entonces, iconos del cine que tienen muy alta recordación en las personas, tienen escenas que muchos narradores utilizan una y otra vez.

\section{-A.D.: Bien. Dame un ejemplo.}

-H.: Recuerdo un escena de Matrix, en donde obviamente se hace el giro de $360^{\circ}$ de la cámara, entonces creo que te he visto a vos -y no me acuerdo a quien más- tratar de utilizar la misma escena en el escenario. Es decir, detienen la acción de los dos personajes y simplemente dan pasitos, parodiando la escena de Matrix. Obviamente todo el mundo sabe de lo que están hablando aunque no se han salido del cuento y saben que no están contando Matrix...

-A.D.: Pero hay una identificación con esa imagen.

-H.: Y están utilizando un recurso evidentemente cinematográfico llevado al arte escénico.

Así, por medio de un espacio de "narración oral" y por una posible interactividad con él, existiria un territorio existencial de auto-referencia tanto del público como de los que están narrando. La imagen del cuento que describe Harry es extraida de los "signos" que pueden ser comprendidos por el público que contribuyen evidentemente con el desarrollo de la obra. Es posible que la oralidad se haya transformado nuevamente, influida por la imagen y la grafia. Ello puede ser el resultado de una adaptación y entremezclas diversas de la tradición oral con el actual mundo de la suscripción por cable y los significados conjugados de MTV o Facebook. Las referencias a la adolescencia de la generación de los 70`s, influenciada directamente por la televisión, es un ejemplo que muestra la entrevista con Harry Marin ${ }^{8}$.

8 Es posible que los cuentos estén cercanos a la identificación pero también a las normas humanas y sociales, idiomas, idiosincrasia y terminología. La incongruencia y el absurdo que se puedan presentar en los espacios de narración, así como la violación de las normas, hacen que el público pueda en 
Así las cosas, es posible que exista una posibilidad de virtualidad en el fenómeno oral. Como bien afirma Alejandro Piscitelli, durante milenios el lenguaje oral fue vehículo único y exclusivo de la comunicación, sociedades simuladas ampliando el concepto y las explicaciones del mundo que rodea al hombre. El campo de batalla de las tecnologías del conocimiento, que van en contra de la memoria oral y sus polisémicas formas de enunciar mundos, se hace presente de nuevo en las comunidades. Es más, ha permanecido en estado latente, en resistencia un arte acumulativo que puede presentarse como una senda alternativa de conocimiento. En las observaciones a los espacios de narración, tomé en claro que los nuevos narradores, aunque respetan la trayectoria de algunos años de otros cuenteros, repiten sus cuentos por considerarlos efectivos, sumándoles elementos más graciosos producto de los "puntos comunes" por el catecismo de las imágenes de video y lo masivo".

\section{En búsqueda del Ágora narrativa y una posible categorización de cuenteros}

Había entonces empezado mi investigación tratando de averiguar la razón del porqué los narradores convocaban a un grupo de escuchas que admite los medios y desea sentarse horas enteras frente a la figura de un cuentero, de la misma manera que puede hacer lo en una red social. En mis reflexiones deseé argumentar que este fenómeno podría estar vinculado con un "paso hacia delante" de la oralidad secundaria, llegando por medio de lo virtual a nuevos ambientes. Me encontré con

algún momento sentirse identificado con lo que se está narrando. Ahora bien dentro del género se presentan tres tipos que investigué en mi incursión por la comedia y que puede ser invocado a beneficio de inventario Sit-Com, estas son: el Actcom, el Domcom y el Dramedy. El Actcom es una comedia de situación basada en la acción y en los malos entendidos que producen hilaridad. Algunos cuenteros llegan a contar estructuras narrativas parecidas al Actcom, como tratar de describir el baño del a casa de la novia y las peripecias de un personaje si no hay agua en el baño. Se encuentra el Domcom o comedia de situación basada en los personajes. Donde hay un sentimiento de recrear el núcleo familiar y las situaciones cotidianas que ocurren al interior de tal grupo familiar. Los narradores como Roberto Nield cuando narran el partido 5 a 0 Colombia Argentina abrazan el nacionalismo y describen las situaciones familiares. El cuento "Instrucciones para vestirse" cuando se es sorprendido en el acto, también se encamina a los valores familiares y los cambios de pensamiento generacional. Y por último donde podemos reflexionar desde la cuentería es el Dramedy o Comedia de situación, basada en la intención o razonamiento que combina elementos con el drama. La comedia dramática, o dramedy, es la forma más rara de todos los tipos de comedia de situación. la sugerencia de que los espacios de cuentería podrian ser considerados "espacios virtuales" e indagué un poco sobre tal hipótesis, llegando a la conclusión de que en efecto poseen los espacios de cuentería una serie de caracteristicas virtuales. Sin embargo no alcanza esas dimensiones si entendemos virtual desde las tecnoculturas. Frente al lenguaje televisivo, la entrevista con Marín me llevo a lo que viene:

\section{-A.D.: ¿Y frente a la televisión?}

-H.: Frente a la televisión hay un lugar común que se ha repetido mucho que es la crítica a un programa que ha durado demasiado que es "Padres e hijos", programa que todo mundo ha visto. Pero también hay recursos de identificación frente a programas de televisión que todos estos muchachos han visto como los de Mazinger- Z, la Abeja Maya, el Capitán Centella, Naruto. Bueno, todas estas escenas típicas que se repiten en estos seriados televisivos, se introducen como un gag dentro de los cuentos.

Con todo, pensando en este punto de la entrevista frente a lo que plantea Debray sobre las parodias de la videósfera en el cine, el individuo se siente solo frente a la pantalla; en la televisión el individuo se siente todo el mundo. En estas "contadas", donde el público se puede sentar a escuchar más de cuatro hora cuentos, en esta "Ágora narrativa", el individuo se cree parte de su entorno y participa activamente en él: la narración oral entendida como cuentería universitaria tiene obra de autor (que es propia del cine) y tiene información en directo e inmediata (característica propia del lenguaje televisivo); los tres pueden dirigirse a las masas.

Uno de los puntos más inquietantes frente a este factor común de la videosfera narrativa, es que de la misma manera que el cine, la oralidad repite argumentos, pero, como la televisión, vedettiza a los narradores. Los narradores alcanzan un nivel de popularidad tal, que, en ocasiones, en los espacios de cuentería no se presta atención a la obra de narración que los narradores presentarán, sino que se tiene preferencia sobre "cuál es el cuentero que cuenta". Y una de las tendencias de los espacios de calle es precisamente que se utiliza en exceso el humor para mantener al público cautivo en las largas jornadas de cuentería. Con el paso de los años, los espacios de narración se han llenado de cuentería llena de humor efectivo e incluso en ocasiones vulgar, convirtiendo, 
incluso los cuentos de tradición oral, en meras representaciones y constantes apartados.

Esto último nos lleva a dos temas paralelos: por un lado, a la entrevista que le hice a un cuentero tradicional y la otra a los hipertextos que pueden tener los relatos que se cuentan, tanto en espacios formales, como callejeros. Después de la entrevista con Harry, me senté a escuchar cuentos y me encontré con un hecho que me parecía rutinario dentro de la cuentería, pero que podría servir para el desarrollo de la investigación: hay una representación constante en un grupo de cuenteros por medio de apartes o pequeños paréntesis que remiten a otras cosas en el desarrollo del relato: podrian ser, más que hiperimágenes (requeririan varios niveles de realidad y simulación), ejemplos de lo hipertextual, porque el narrador entra y sale en esas referencias o paréntesis, alejándose del desarrollo real del cuento. Entre más acápites o paréntesis abría el narrador, más difícil se le hacia retornar al cuento. Así que buscando la identificación con su público, le presenta una serie de entradas y salidas del texto como tal, dejando simple hilaridad en lo cotidiano y en las imágenes, alejándose de aquellas visualidades sacras de los primeros momentos de la oralidad que rescataba la memoria y hacia presente lo antiguo.

En este punto se nos mostró que debe existir un terreno necesario entre el artista y su público donde podría existir una des-privatización de la mirada individual: hay punto de encuentro, un Ágora narrativa que no deja que el cuento se diluya en representaciones e identificaciones.

En una primera entrevista realizada a Omar Díaz, "Juansinmiedo", supe que nació en San José del Palmar, Chocó y es abogado de profesión pero no ejerce. Estudió artes escénicas en una compañia latinoamericana de teatro y es un referente real del movimiento de narradores desde que éste nació.

En la entrevista que le realicé a "Juan" para la presente investigación, discutimos frente a un tema muy inquietante que es la anonimización. Siendo la cuentería un lenguaje oral, en el momento en que se cuenta la obra, ella deja de ser del narrador que la hizo y empieza a fluir dentro de lo oral. Los derechos de autor son producto de nuestra cultura gráfica y es muy complejo (hablo desde mi experiencia como narrador) hacer respetar una obra de narración por las dinámicas orales que llevan en su génesis. Al final de la segunda entrevista le pregunté sobre el particular a un cuentero que ha tenido que lidiar constantemente con ese fenómeno. "Juansinmiedo" rescató un cuento de tradición de Remedios, Antioquia llamado "La mujer mágica". Este cuento lo transformó Juan Carlos Grisales para volverlo "Patricia la bella": una mujer que tiene tres pretendien-tes y que les pone una prueba el mismo día a la misma hora en el cementerio. Uno debe llevar un ataúd y dormir en él; otro debe rezar frente a un ataúd (si saber que allí adentro hay alguien vivo); y el tercero debe disfrazarse de diablo para asustar al que esté en el cementerio: sucede la acción y los tres caen o muertos o desmayados. El cuento, que puede contarse en diez minutos, ha sido alargado por los jovenes narradores hasta una hora y media llenándolo de hilaridad pero tratando de mantener la esencia del cuento con una moraleja que justifique de nuevo esa esperanza estética de un cuento.

-A.D.: ¿Tú sientes que el cuento se vuelve anónimo por el hecho de ser oral?

-O: Hay un problema con la tradición oral y es que no se le puede reclamar derechos de autor. Lo único que uno puede reclamar en la tradición oral es "yo hice la recopilación o la investigación". Como el caso de cuentos que los han cogido y los han cambiado. Yo no puedo decir: "ese cuento es mío", porque es tradición oral. Lo que yo le he hecho al cuento es rescatarlo, recopilarlo y darlo a conocer.

En el nuevo movimiento de cuenteros, la mayoría de ellos esperan a que se haga el trabajo: a que uno se siente, lo escriba, lo redacte y lo ponga ante el público para ver cómo suena. Cuando uno tiene el cuento moldeado y construido, ellos lo cogen; le cambian tres o cuatro cosas y dicen "esto es mio". Entonces lo que yo veo de grave en estos jóvenes es que no están creando, están pegados de lo que uno les da. Si el día de mañana los cuenteros viejos o los de segunda generación, dejamos de proponerles trabajo, se mueren porque no tienen qué contar, porque estoy seguro de que no son capaces de crear algo. Yo escuchaba a un joven que dice que es cuentero, decir: "tengo que pagar una función de fulano, para ver si me aprendo dos cuentos más porque estoy mamado de contar los que ya me sé". 
El esoterismo teatral presente en el discurso oral hace en el movimiento que los cuentos y obras que realizan narradores orales de renombre, sean deseadas por otros para lograr el triunfo de lo humorístico, de la ironía romántica: no hagáis nada, sed alguien. Aquí sería: no elaboréis cuentos, sed cuentero por alguien. Estos nuevos narradores, los que fueron denominados en su momento "chisteros", se encuentran más cerca de las líneas de lo mediático por medio de las repeticiones constantes de cuentos que consideran de impacto. Por ello, cuando pasé a contar al frente invitado como uno de los "gurús" en la narración, "Juansinmiedo" me decía que no contara lo nuevo que tengo sino lo viejo para que no sigan fluyendo las copias (MartínBarbero, 1992)..$^{10}$ Justamente aquí encontré algunas tipificaciones que acompañarian las sugerencias presentadas en el ensayo.

Los narradores tradicionales que rescatan los cuentos de tradición en los pueblos y que hacen una verdadera etnografia de lo oral, no hacen tantas referencias al mundo actual, sino más bien desde la diferencia y la comparación de los tiempos anteriores. Esos primeros narradores frente al movimiento universitario, deciden recurrir a herramientas parecidas a las que ven de los cuenteros urbanos en miras a que el público entienda la tradición oral.

Yo estoy entre los narradores de la segunda sugerencia o los cuenteros universitarios. Vengo de la academia y después de observar que la cuentería podía ser más que una terapia para mi tartamudez, empecé a contar cuentos de literatura y de mi propia cosecha dejando de lado lentamente la repetición y encaminándome a mi propio estilo. Encontraban textos literarios y los adaptaban al lenguaje oral: pueden o no escogerse dentro del ambiente en el que cuentan, alejándose con las historias o incluyéndose para generar atención en el público.

10 Repetición o variación de un cuento idéntico partiendo de un prototipo o matriz. Ejemplo: el conjunto de cuentos urbanos que toman como modelo el clásico el relato adolescente frente al cuento que puede responder a las características propias del melodrama televisivo. Es cierto En el capítulo 2 de Televisión y Melodrama el Antropólogo y filosofo Jesús Martín-Barbero nos recrea la historia del fenómeno melodramático que tiene como genealogía los relatos de Francia e Inglaterra a finales del siglo XVIII. Allí Martín-Barbero, menciona como partes importantes cuatro sentimientos básicos que son a saber: "El miedo, entusiasmo, lástima y risa- a ellos se hace corresponder cuatro tipos de situaciones que son al mismo tiempo sensaciones -terribles, excitantes, tiernas y burlescas- personificadas o 'vividas' por cuatro personajes -el traidor, el justiciero, la víctima y el bobo- que al juntarse realizan la revoltura de cuatro géneros: novela negra, epopeya, tragedia y comedia".
Los "chisteros" o, denominados por el movimiento, los cuenteros Lycra, utilizan el humor no como medio, sino como fin de sus narraciones; se dedican a repetir lo que escuchan sin tener una propuesta escénica real y mejorada de las historias. Alargan los cuentos con elementos de hilaridad y sus historias podrian estar plagadas de acápites sin llegar al cuento concreto. Estos cuenteros piensan que su audiencia es una clientela, entrando asi a un entropía que puede llevar a acabar las nuevas propuestas narrativas y creando una relación con su público basada un poco en la vedettizacion de la figura del cuentero.

En medio de tales categorias, existen los ultra ortodoxos de la narración oral que no van a un espacio de cuentería universitaria ni callejera, porque hay que elaborar "puestas" en escena de la narración oral escénica. Ellos, denominados "garzonianos" (por las teorias de Garzón Céspedes el cubano que llego a Colombia en 1988) o puristas, son dificiles de consultar, dado el gran abismo entre ellos y los cuenteros universitarios, pero que también avanzan en vastas puesta escénicas y nuevos montajes con estéticas cercanas al drama.

\section{Para terminar, una repetición positiva: la creación y recreación de la obra de cuentería por los cuenteros}

Los cuenteros con cartón son los cuenteros que comenzaron como universitarios y al paso del tiempo se dedicaron a sus profesiones. Estos cuenteros dejan a un lado el concepto de cuenteria, vista como un medio para sobrevivir, y se dedican a contar por el mero placer de hacerlo. En ocasiones, estos cuenteros con reconocimiento, cobran cifras muy altas por sus presentaciones y, paradójicamente, pueden asistir a un espacio de cuenteria y hacerlo gratis. Los cuenteros que viven de la cuentería, ven con cierto recelo a estos cuenteros con "cartón" profesional y argumentan que no son artistas porque "no están dedicados al arte". Su itinerancia dentro del movimiento, les permite crear historias que son siempre novedosas y bien recibidas por el público que asiste a las jornadas de cuenteria. Son narradores que pueden contar todo tipo de cuento dependiendo de su proceso como narrador en la escogencia de su obra. Utilizan las herramientas mediáticas para hacer los cuentos más agradables para el público; no importa si son cuentos de tradición o cuentos urbanos. Ellos representan el punto 
de mixtura más alto en la clasificación que elaboré en la investigación.

Cuando toman un cuento de otro, siempre dicen cuál es su autor, con plena autorización del creador. Lo que realizan son "opus", interpretaciones de un texto desde su punto de vista.

\section{Conclusión}

Para concluir este trabajo deseé analizar una historia que es contada de dos maneras diferentes: un cuento sobre un guerrero que tiene que huir de la muerte para ganar el corazón de la princesa del reino de la China. Esta historia es contada por Harry Marin y en ella el guerrero huye de las flechas que le tiran los guerreros de la gran muralla. La otra versión es mía con algunas grandes diferencias y con las herramientas propias de un estilo más universitario que literario. El día de la narratón decidimos contar la misma historia en sus dos versiones: una después de la otra, con un resultado muy emotivo para nosotros los narradores y para el público asistente a la cuentería ese día. Harry contó primero su versión y cuando comencé a contar la mía, surgió la imagen de una mujer con un listón púrpura; tal imagen se me habia olvidado hasta ese momento: como un homenaje a aquel temeroso cuentero tartamudo, dejé que uno de los protagonistas de la historia basara su imagen en la mujer y un listón púrpura. Terminé la historia con todas las imágenes en mi cabeza, con la sensación real que algún día en algún momento, alguien contará la misma narración y no se preguntará por qué la princesa tiene un listón en el cabello. Cuando me alcance por fin el fin de esa historia, desearé estar incluido en esas imágenes para pervivir un poco en la memoria de otros.

La investigación me deja más interrogantes vivos que respuestas establecidas. La reflexión sobre la cuentería como un hecho virtual me hizo cambiar un poco el enfoque de lo que venía realizando. Pero con todo, pude elaborar unas categorias sobre las herramientas posibles que existen en la urdimbre actual y que sirven a los narradores para continuar sus relatos.

No es absurdo pensar que el movimiento de "Cuentería Universitaria" sea una representación del pensamiento de algunos jóvenes de las últimas tres generaciones, que sienten limitadas sus posibilidades de expresión y buscan la manera de manifestar sus sentimientos, vida cotidiana, miedos e incluso valores morales. Hombres y mujeres, sujetos de conglomerados sociales que quieren verse reflejados en alguien que represente su entorno y a sí mismos, un aeda que cante sus canciones y que haga público su sentir de resistencia frente a lo global.

Es por ello que queda en la investigación un sabor que me muestra que, todavía en el mundo de lo inmediato y lo fugaz, se está buscando y accediendo a nuevas tradiciones. Los encuentros con el otro se manifiestan en este posible nuevo tipo de tradición. Antaño, la tradición estaba encaminada a retomar la Mnemosyne, el recuerdo. Ahora, el recuerdo se hace efectivo con las historias que se cuentan y las herramientas que utilizan. A continuación presentaré una posible matriz de las herramientas que los cuenteros universitarios-urbanos, los de calle e incluso algunos cuenteros tradicionales, utilizan en la puesta al público de sus cuentos.

En el futuro de los entrecruces y la hibridación, los multi-relatos pueden encontrar eco en la oralidad terciaria (tal vez estamos en este tipo de oralidad para que se convierta en una verdadera alternativa de significados simbólicos) (Martín-Barbero). La interpretación polisémica de las narraciones que rescatan la tradición y la dotan de un aura mediática, seguirá generando historias con un alto contenido de herramientas actuales que deben tener una "memoria oral participante", es decir, que algunos cuenteros además de escuchar y elaborar relatos, mantenerlos y repetirlos, deberían tener la preocupación de un registro audiovisual de la obra de cuentería que elaboran. Pero para que tal acto no se convierta simplemente en el rescate del mero hecho anecdótico, el narrador debería organizar un registro de las diferentes formas en que él esta narrando una misma historia, o cómo sus iguales elaboran interpretaciones de los mismos textos narrativos o los suyos propios. Tal memoria oral participante, ensancharia la dinámica de la cuenteria, además de dotarla de un aura dinámica y creadora. Se podrian encontrar los elementos comunes de los relatos que actualmente se cuentan y se identificarian con mayor claridad las herramientas mediáticas que se utilizan en un conglomerado social determinado, y sus significaciones en sus "mundos de la vida". 
No sabemos si realmente estamos en la nueva era de lo neomediático o tal vez tendríamos que hablar de la oralidad intramediática, pero lo cierto es que las narraciones que acompañan y delinean a un grupo humano, ya sean creaciones llenas de cotidianidad humorista o de trascendencia reaccionaria, enuncian la época y el contexto en el que se extienden, y es importante una recopilación de tal riqueza. No podemos ignorar que nuevos lenguajes y significados surgen con lo que se ofrece en los medios. Nuevas palabras y relatos anuncian que, en efecto, estamos destinados a ser nuevos traductores en medio de los nuevos significados que se le asignan al arte de sentirse parte de un conglomerado por medio de las palabras.

Traductores multimediales: seguramente eso podía ser el futuro de la oralidad. 


\section{Referencias}

1. Abadía Morales, G. (1994). Cuento urbano en el Salitre (2005, 8 de mayo). EI Tiempo. Pp. 2-4. El correo de las Brujas y la Literatura Oral. Colombia: Tres Culturas Editores.

2. Benjamín, W. (1982). "La obra de arte en la época de su reproductibilidad técnica" en Discursos Interrumpidos I. Madrid:Taurus.

3. Bisonte, M. E. (2005). ¿ Siempre la misma historia? Miradas, número 8.

4. Cadavid, R. (2004). "Narración oral y transmutación tras la búsqueda de los orígenes mágicos de nuestra palabra". Ponencia del Primer congreso internacional de la Oralidad. Bucaramanga.

5. Calibrase, O. (1987). La era neobarroca. Madrid: Cátedra.

6. Chernilo Steiner, D. (1990) Integración y diferenciación: la teoría de los medios simbólicamente generalizados como programa progresivo de investigación. Cinta Moebio, número 6. Facultad de Ciencias Sociales. Universidad de Chile.

7. De Zubiría Samper, S. (1999). "Momentos de la identidad cultural latinoamericana" en Cultura: Teorías y Gestión. Ediciones Uninariño.

8. Debray, R. (1994). Vida y muerte de la Imagen. Barcelona: Paidós.

9. Enríquez, J. R. La telenovela y el fin del Melodrama. $h$ ttp://www.felafacs.org/ dialogos. Consultado el 10 de mayo de 2011.

10. Escobar, A. (1999) El final del Salvaje, CEREC e ICAN Bogotá.
11. Fuenzalida, V. (2002). Televisión abierta y audiencia en América latina. Buenos Aires: Grupo Editorial Norma.

12. Guillermo, S. (2002). La prensa sensacionalista y los sectores populares. Bogotá: Grupo editorial Norma.

13. Lull, J. (1997). Medios de la comunicación y cultura. Buenos Aires: Amorrorio.

14. Martín-Barbero, J. \& Muñoz, S. (Coordinadores). (1992). Televisión y melodrama: Géneros y lecturas de la telenovela en Colombia. Bogotá: Tercer mundo.

15. Martín-Barbero, J. (1999). Aventuras de un cartógrafo mestizo en el campo de la comunicación. Revista Latina de Comunicación Social, número 19, Pp. 4.

16. Mazzioti, N. (2001). Televisión pública: del consumidor al ciudadano. En Rincón, O. (comp.), Televisión pública: del consumidor al ciudadano, Bogotá : Fes/ secab.

17. Mena, M S. \& Turk, E. La niñera versión argentina. Universidad de morón. Facultad de ciencias económicas.

18. Mercado, J. (1995). Literatura oral del Caribe colombiano: Narrativa. Bogotá: Universidad Distrital Francisco José de Caldas.

19. Morley, D. (1996). Televisión, audiencias y estudios culturales. Buenos Aires: Amorrortu.

20. Murillo, D. (1999).Comunicación y oralidad. Razón y Palabra. 15 (14).

21. Ong, W. (1996). Oralidad y Escritura: Tecnologías de la palabra. Bogotá: Fondo de Cultura económica.

22. Pérez Beltrán, A. M. (2002). "Unicuento: Un sueño hecho palabra" 
Corporación huellas de paz . Universidad Santiago de Cali.

23. Pérez Beltrán, A. M. (2004). "Del espacio de cuentería universitaria al aula de clase." Conferencia realizada en el Marco del Abrapalabra, Bucaramanga, Agosto-Septiembre.

24. Pérez Beltrán, A. M. (1999). Revive la palabra: del espacio de cuentería universitaria al aula de clase. Bogotá: Ediciones Uniandes.

25. Piscitelli, A. (2002). Meta-Cultura: el eclipse de los medios masivos en la era de la Internet. Buenos Aires: La Crujía Ediciones.

26. Quéau, P. (19995). Lo virtual: virtudes $y$ vértigos. Barcelona: Ediciones Paidós.

27. Rodari. (1985). Gramática de la Fantasía. Barcelona: Reforma de la Escuela.

28. Rodríguez, J A. (2011). La Narración oral escénica (NOE): Un género híbrido "El caso de los cuenteros universitarios de Bogotá: Algunas consideraciones teóricas y entrevista con el narrador Jaime Riascos Villegas" en el artículo virtual "Literatura, posmodernidad y otras yerbas." Universidad Javeriana.

29. Thompson, J. B. (1998). Los media y la modernidad: una teoría de los medios de comunicación. Barcelona: Paidós.

30. Tono, L. (1995). Los desafíos de la oralidad: similitudes y diferencias entre oralidad y escritura. Texto y contexto, número 28. Universidad de los Andes.

31. Varela, M. "Culturas populares, recepción y política. Genealogías de los estudios de comunicación y cultura" En: Daniel Mato (coord.): Estudios y Otras Prácticas Intelectuales Latinoamericanas en Cultura y Poder. Caracas: Consejo Latinoamericano de Ciencias Sociales (CLACSO) y CEAP, FACES. Universidad Central de Venezuela
32. Versión del Resultado del jurado del Concurso internacional de narración oral. Bucaramanga. Agosto 2004.

33. Vich, V. et al. (2007). Oralidad y Poder. Bogotá: Editorial Norma.

34. Web: Blog http://fashionmedia. blogspot.com/2008/03/moda-y-globalizacin-prdida-de-la.html consultado el día junio 16 de 2010. 